\title{
Assessment of the use of problem- orientated, small-group discussion for learning of a fixed prosthodontic, simulation laboratory course
}

\author{
M. G. Botelho' and D. O'Donnell'
}

\begin{abstract}
Aim To evaluate a simulation laboratory course that used student-centred smallgroup problem-orientated discussion activities as the main medium of instruction. Methods A structured questionnaire using a six-point Likert scale with 30 statements relating to a fixed prosthodontics course was distributed to 4 th-year and 5 th-year students who had completed the course.

Results A 93\% response rate was achieved for both years with a mean score for the 4th-year being $94.2( \pm 13.7)$ and the 5 th-year $107.5( \pm 16.9)$. The differences between the scores of both years are highly significant $(\mathrm{P}=0.0006)$ indicating that the 5 thyear were more favourable about the course and learning approach used.

Consistency and reliability of the questionnaire was judged reliable according to Cronbach's alpha ( 4 th-year $=0.7,5$ th-year $=0.83$ ). Many aspects of the small-group student-centred activities were highly valued by students however, students expressed a preference for learning and interacting with teachers than colleagues. Conclusion Small-group student-centred learning activities were reported as creating an active, safe learning environment with beneficial opportunities for peerpeer interaction such as questioning, teaching and learning from students. However, students expressed a preference for teacher-centred information dissemination and activities. An understanding of the rationale of student dependence to teachercentred learning may allow improved modifications in a student-centred learning environment.
\end{abstract}

educational and ideological principles. ${ }^{1}$ However, it is most likely that the benefit is formed from a combination of these principles. ${ }^{2}$ Learning is said to be enhanced when students are involved and enjoying themselves (motivational principle). Motivational theories of learning support the use of non-competitive group activities rather than individual competitive activities as learning in groups helps classmates learn. In such groups students encourage one another's learning and reinforce one another's academic efforts and express behaviour favouring academic achievement. ${ }^{3}$

In small groups, learners have the opportunity to interact, question and elaborate with peers more frequently than they can in a teacher-centred environment, thus enhancing learning and understanding (educational principle). The importance of student to student interaction should not be underestimated as it is considered to be an interaction that most influences student performance in instructional situations. ${ }^{4}$ Interaction amongst learners in relation to appropriate tasks has been shown to increase the mastery of critical concepts 5 and interactions such as peer teaching has found achievement benefits for both the tutor and tutee. ${ }^{6}$ Also, the process of elaboration of knowledge in a learning activity has been shown to allow information to be better understood, processed and retrieved. ${ }^{7}$

Lastly, working in groups also allows students to learn life skills such as how to

\section{In brief}

- Small-group student-centred learning creates a safe and active learning environment for all abilities of learners to participate freely in the educational process.

- Knowledge sharing and interaction is fundamental for enhanced learning in a small-group student-centred environment.

- The process of elaboration of previous experiences and knowledge has been shown to promote better learning for both the student 'tutor' and tutee.

- Despite various reported benefits students still expressed a preference of learning from content expert tutors. This may reflect a conflict in learning approaches that exists with a course embedded within traditional curriculum, or reflect an insecurity from learners trying to cope with a new 'teaching' approach.

work collaboratively and democratically with peers as well as communication and interaction skills (ideological principle). ${ }^{1}$ Peer teaching has also been shown to be more effective than tutor-centred teaching, ${ }^{8}$ 
which may be attributed to students feeling more comfortable with asking questions and discussing problems with their peers rather than interacting with authoritative figures.

The use of small groups for learning creates a non-threatening environment that allows all students to participate in discussions that they may not have the opportunity to do in a large group environment. Also the use of small groups creates a safe environment in which students can ask questions of their peers which they may not normally do to staff members for fear of asking the 'stupid' question. Another benefit from working in groups is called 'process gain', and is said to occur when solutions and ideas result from the group effort of sharing and generating information occurs. This does not happen when working alone in a tutor-centred scenario. ${ }^{9}$

\section{The fixed partial denture course}

The learning for the fixed partial denture (FPD) course was designed to be mainly driven through small-group discussion activities based on problem-orientated activities that were student-centred. A series of worksheets was used containing questions relating to problem scenarios to address appropriate areas of knowledge, decision-making, treatment planning or problem-solving relating to fixed partial dentures. Many of the questions from the worksheets were designed so that prior knowledge and personal experience had to be applied to solve the problem statements from first principles. It was presumed that students would not be able to individually answer all the questions on the problemorientated worksheet, and that collaborative activity would be required to find the solutions.

Students were given worksheets in the simulation laboratory session where they completed the assignments in groups of 3-4 after which they formed larger groups of 6-8 and they fed back and discussed the answers with the tutor. Worksheets were also given out for individual home study and subsequently discussed in a similar manner. During the small-group discussion of the worksheets tutors moved between groups observing students and giving assistance or clarification in understanding of the worksheets. There was approximately one member of staff to 12-16 students, meaning that tutors would discuss the worksheets at different times during the session to work through the class. Tutors were requested to use a questioning based approach in the debriefing of the worksheet to derive, rather than simply give the answers.

The 'lecture course' comprised of nine 50 minute sessions although these 'lectures' were also student-centred with the use of similar problem-oriented worksheets as well as clinical slides. Students worked on the worksheet in smaller groups of 2-3 and did not form larger groups because of the physical constraints of the lecture theatre. Small groups would then feedback their answers to the tutor.

During the simulation laboratory and 'lecture' time slots was a total of 24 different worksheets discussed ranging from 'preparation problems' and 'temporisation' to 'longevity of bridges' and 'checking laboratory work'. Four of the worksheets were in relation to a simulated 'patient' in a clinical scenario. This addressed determining patients' wants and needs and the appropriate questioning required of the 'patient' to determine a definitive treatment plan.

Clinical demonstrations were confined to abutment tooth preparations and subsequent temporisation. For conventional FPD preparations and temporisation an in-house video was used to demonstrate the appropriate clinical skills procedure. Subsequent tutor demonstrations and comments were given when it was recognised that there were practical problems or issues common amongst many students. Of the time in the simulation laboratory, approximately $2-2 \frac{1}{2}$ hours would have been spent on clinical skills and $1-1 \frac{1 / 4}{4}$ on the small-group activities.

It is difficult to determine how much of the course was delivered in a traditional tutor-centred approach, however approximately two thirds of the 'lecture' time and simulation laboratory sessions would have been student-centred with the remaining 'tutor-centred' time allocated to briefing of the problem exercise, feedback on answers and questioning to lead students to the correct solution. The time required by staff in each session would have been identical to other simulation laboratory courses, however the actual 'teaching' time would have been slightly less because of the studentcentred nature of the learning activities. However, as with any teaching and learning innovation, significant time was required to establish and develop the course content.

The knowledge aim of the course was not simply to teach the psychomotor skills associated with FPD abutment preparations and subsequent temporisation but also to develop decision-making and problemsolving skills in a clinical context. Such decision-making or problem-solving may be in relation to treatment planning, determining patients' wants and needs or reporting on findings from special investigations or problem-solving clinical scenarios.

Students were also asked to perform selfevaluation for all tooth preparations and temporary restorations using a structured pro forma relating to features of their tooth preparations and temporisation before seeking assistance from a clinical tutor. Students were encouraged to seek assistance from peers in connection to problems or questions they had with their practical work. Students were assessed on the validity of their self evaluation by clinical tutors.

A selection of the types of questions or problem scenarios contained in the worksheets is given in Figure 1.

\section{Learning theory supporting this approach}

The small-group activities in this course were problem-orientated relating to possible clinical problem or situations. The learning in such an environment suits the information processing approach to learning. ${ }^{10}$ According to this theory, 3 principles play a significant part in the process of learning: activation of prior knowledge, encoding specificity and elaboration of knowledge. Prior knowledge is used to understand new information or problemsolving scenarios. The way prior knowledge is embedded in the long-term memory will determine what is understood from the 


\section{EDUCATION learning}

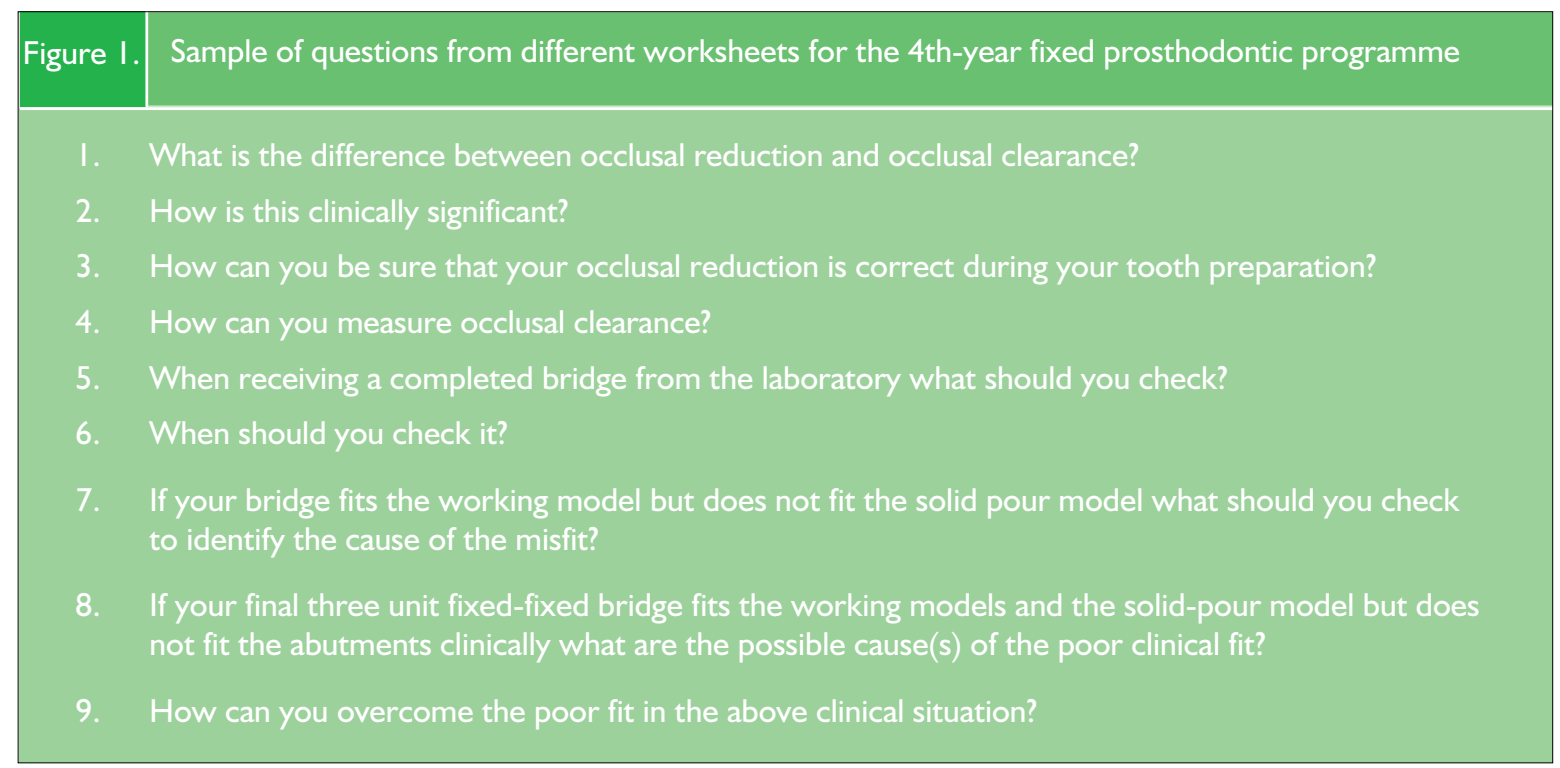

new learning opportunity and this, in turn, will define what is learned from it. ${ }^{11}$ Encoding specificity requires that for successful retrieval of information in the future, the problem trigger that is to reactivate the knowledge be encoded with the required information at the time of learning. Simply put, the closer the resemblance between the situation in which something is learned and this situation in which it is applied, the better the performance. ${ }^{12}$ The last principle relates to the elaboration of knowledge. Information is better understood, processed and retrieved if learners have the opportunity to elaborate on that information. ${ }^{7}$ The elaborations appropriate to this programme may be in the form of discussion with peers ${ }^{11}$ or teaching peers ${ }^{13}$ and so is facilitated by small groups.

The aim of this study was to evaluate the use of small-group, student-centred, problem-orientated learning activities on the learning experience of a clinical simulation laboratory course.

\section{Materials and method}

A 30-statement Likert-type ${ }^{14}$ scale questionnaire was distributed to two consecutive years of dental students at the Prince Philip Dental Hospital. These were 4thyear and 5th-year students. The 4th-year students had just completed the fixed prosthodontic course and the 5th-year had completed the same course the previous year. The statements were derived from previous, non-validated, student evaluations of the fixed prosthodontic course and comments from staff-student interactions. The scale questionnaire is seen in Figure 2. Half the statements were worded favourably toward small group learning, or positively, and half were worded unfavourably toward small group learning, or negatively. This was to make the respondents think about the statements rather than respond automatically. It also minimises the effect of a response set towards either agreement or disagreement with whatever statement is made. ${ }^{15}$

\section{Scoring the scale/questionnaire}

It is not mandatory to adhere to the original Likert format, and a larger or smaller number of response categories can be used. A modified six-point Likert scale was used with possible responses ranging from agree very much $(+3)$ to disagree very much $(-3)$ and with no 'undecided' category. The signs of the respondent's scores for statements $1,3,5,8,11,12,13$, $14,16,19,20,22,28$ and 30 are reversed. The scores are summated algebraically, the sign of the total is reversed and a constant is added $(3 \times 30=90)$. The range of the scale questionnaire is 0 to 180 . The algebraic summation of the scores of the individual's responses to all separate items gives the total score, which is interpreted as representing the respondent's attitude or opinion towards the subject in question.

A Likert scale is an ordinal scale, and so individual scores cannot be interpreted as absolute values and are only interpreted in terms of how they compare with other people taking the test under similar conditions. Likert scales provide a relatively accurate basis for the ordering of people on the characteristic being measured.

\section{Results}

A total of 514 th-year undergraduate dental students, and 43 5th-year students returned their completed scale questionnaires. This represented a response rate of $93 \%$ for both years. The 5th-year was divided into 16 females and 27 males, and the 4 th-year into 17 females and 34 males.

The scores for both 4 th- and 5th-year were normally distributed. This means that even though the scale is an ordinal scale, parametric statistical analysis can be applied.

The mean score for the 4th-year was 94.2 with a standard deviation of 13.7. The mean score for the 5th-year was 107.5 with a standard deviation of 16 .9. There was no sexual dimorphism in the mean scores for either year $(\mathrm{p}=>0.05)$. 
I found the Fixed Prosthodontic Course useful

2. The learning approach used in this Fixed prosthodontic course is no different to that used on other techniques courses I have experienced

3. The small group learning activities (2-4) students in this course forced students to be more active participants in comparison to normal groups $(7-8)$ students

4. Tutor centred learning (i.e. tutor telling me what/when/how to do it) with little or no discussion opportunities helps my learning.

5. The worksheet tasks used in this course were relevant to my future use of clinical skills for the provision of fixed prostheses.

6. The use of discussion in small groups with my colleagues did not enhance my learning.

7. After small group discussion with colleagues I feel more comfortable asking a tutor a question about the discussed problem or issue.

8. I enjoy the opportunity for discussion in small groups.

9. I asked less questions in the small group, student centred discussion environment, than I normally do in a teacher centred, no discussion environment.

10. The opportunity for discussion activities in small groups allowed me to clarify any questions I might have had.

11. The opportunity for small group discussions allowed me to ask more questions of my colleagues than I would in tutor centred classes.

12. In small group (2-4 students) discussions I feel I have a responsibility to help my colleagues learn.

13. The discussion of worksheets in small groups allowed me opportunities to explain concepts to my colleagues.

14. I asked more questions of my colleagues relating to problems with my tooth preparation than I normally would in techniques sessions that are teacher centred.

15. Asking questions of a colleague in the small groups is more threatening than asking a question to a tutor.

16. I enjoy explaining and teaching things to my colleagues in small groups.

17. I prefer being given the correct information on how and why something is done rather than to work it out from previous knowledge and first principles.

18. I do not enjoy sharing information with colleagues.

19. I learnt useful information from my colleagues on this course.

20. I understand explanations from colleagues as well as from tutors, as colleagues use simpler terminology, language and an explanation that I can understand.

21. I feel that I do not have a responsibility to my colleagues to participate in group discussions.

22. I learnt better in the theory sessions that were student centred and in small groups than conventional teacher centred lectures.

23. I prefer learning from teachers than from my colleagues.

24. I prefer learning with the use of large group lectures opposed to learning in small group activities.

25. The use of theory sessions in the simulation laboratory that were student centred and involved small group activities were not as interesting as teacher centred activities.

26. I prefer asking questions to staff than to colleagues.

27. In relation to asking questions of a tutor about a topic, I feel less comfortable asking questions after having small group discussions relating to the topic.

28. I sometimes feel uncomfortable asking a question of a teacher in the clinic or simulation laboratory.

29. The use of the self evaluation form on tooth preparations is not a good way to encourage critical thinking about the procedures performed.

30. In the small group discussions activities I felt I was learning and understanding the material as the discussion proceeded

The percentile curves for the scores of both years are seen in Figure 3. The differences between the scores of the 4 th- and 5 th-years are highly significant $(\mathrm{p}=0.006)$ indicating that the 5th-year were more favourably inclined to the course than the 4th-years.

Scale, internal consistency and reliability was measured by Cronbach's ${ }^{16}$ alpha which was 0.7 for the 4 th-year and 0.83 for the 5 th-year. This indicates that the scale is a reliable instrument for the population under study.

An initial factor analysis of principal components was performed on the scores and an examination of the un-rotated factor matrix and the application of Cattell's ${ }^{17}$ scree test supported the retention of three interpretable factors. Three factors were retained and a three factor analysis was performed. This analysis on the principal components to three factor groups accounted for $42.5 \%$ and $51.2 \%$ of the variance for the 4th- and 5th-year scores respectively.

The percentage positive agreements for each statement for year 4 and year 5 are seen in table 1. From the individual statement scores it can be seen that in general terms the course method of teaching was well accepted with the 5th-year who were more positive about the course than the 4th-year.

The scale questionnaire statements can be categorised into 5 specific groupings, for convenience the percentage agreement with the statement is combined and given in parenthesis.

\section{Outcomes of small group activities}

Both years of students strongly agreed that the use of small groups engages students to be active participants (Q.3. $79.5 \%)$ and allows students to ask more questions of their peers than in a tutorcentred environment (Q.11. 83\%). Students strongly agreed that they learnt useful information from their peers (Q.19. 75\%) and that they enjoyed both sharing information (Q.18. 84.5\%) and teaching peers in small groups (Q.16. $65.5 \%)$. Students also strongly felt they had a responsibility to participate in the activities (Q.21. 86\%). 


\section{EDUCATION learning}

\author{
Figure 3. Percentile \\ curves for the 4th \\ and 5th Years
}

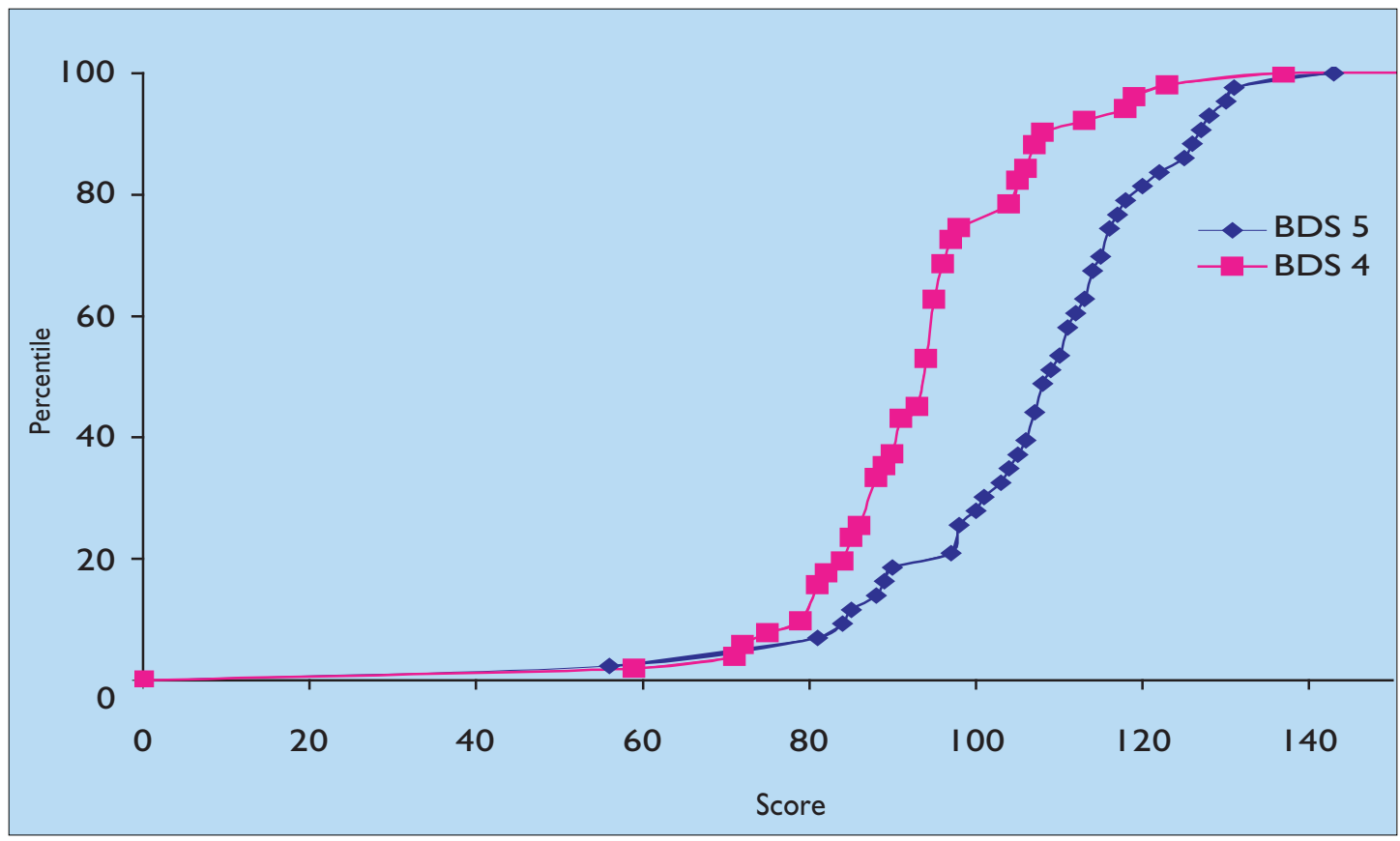

Outcome of discussion activities

Students strongly agreed that: they enjoyed the discussion activities (Q.8. 83\%), that discussion allows for more questioning than conventional teacher-centred environment (Q.11. 83\%) and that discussion allows for the opportunity of clarification of questions (Q10. 84\%). Students also reported that: the discussion process allows students to teach peers (Q.13.65.5\%), that small group discussion enhances learning (Q.6. 75\%) and that students were learning and understanding as the discussion proceeded (Q.30. 74.5\%). Students also reported they felt more comfortable asking questions from staff after discussion (Q.27. $61 \%)$.

\section{Course structure}

Students strongly agreed that this course was different from other clinical skills techniques courses (Q.2. 70\%) and that the course was useful and that worksheets were relevant (Q.1. 77.5\%, and Q.5 63.5\%). The use of self-evaluation tooth preparation forms did encourage critical thinking (Q.29. 70.5\%) and overall they consulted their peers about their tooth preparations more than in other simulation laboratory courses (Q.14.61\%). Learning preference

While students agreed that tutor-centred teaching, with little or no discussion, does not help their learning (Q.4. 60.5\%) they reported relative indifference in their preference to learning with large group lectures or small groups (Q.24. 49.5\%). Students also prefer being given correct information rather than work something out from first principles (Q.17. 80.5\%) and a strong preference in learning from teachers than from colleagues (Q.23. 77\%). There was strong agreement with 4th-year students that they felt they learnt better in conventional lectures than in student centred tutorials (Q.22. 76\%). However, the 5th-years showed only marginal agreement (Q.22.51\%).

Peer-teacher and peer-peer interaction

While students reported that they agreed they had a responsibility to help their peers learn (Q.12. 65.5\%) there was a much stronger agreement that they felt they had a responsibility to participate in group discussions (Q.21. 86\%). Students strongly agreed that asking a question of a peer is much less threatening than asking a tutor (Q.15. 82\%) and that they felt more comfortable asking questions to staff after a discussion period (Q.7 71\%, and 27. 61\%). Students interestingly reported that they understood explanations equally as well as from peers as those from staff because colleagues used simpler terminology or language than a content expert may use (Q.20.
$81 \%)$. However, students expressed a preference in asking questions of staff rather than peers (Q.26. 58.5\%).

There were two questions where the groups of students appeared to differ. Statement 14 relating to peer-peer interactions where $77 \%$ of 5 th-year students agreed but $55 \%$ of 4 th-year students disagreed and statement 22 where $51 \%$ of 5 th-year students agreed with the statement but $76 \%$ of 4 th- year students disagreed.

\section{Discussion}

The use of small-group problem-orientated discussion activities appeared to meet the educational objectives in creating an active, non-threatening learning environment, where students can freely question, share knowledge and learn from one another. Such interactions can allow greater understanding of the problem from a conceptual and comprehension point as students with different knowledge levels and English understanding can clarify key words and the meaning and content of the question or problem. Group participation appears to be valued as an enjoyable process as well as increasing motivation and responsibility. The outcome of these activities helps validate the use of small-group activities in that stu- 
Table I. Individual statement scores for the 4th-Year and 5th-Year

\begin{tabular}{|c|c|c|c|c|c|c|c|c|c|c|c|c|c|c|}
\hline & & & 4th $Y$ & ear & & & & & & 5th & Year & & & \\
\hline & -3 & -2 & $-I$ & I & 2 & 3 & Total & -3 & -2 & -1 & I & 2 & 3 & Total \\
\hline Statement & $\%$ & $\%$ & $\%$ & $\%$ & $\%$ & $\%$ & $\%$ & $\%$ & $\%$ & $\%$ & $\%$ & $\%$ & $\%$ & $\%$ \\
\hline I & 0.0 & 9.8 & 19.6 & 37.3 & 27.5 & 5.9 & +71 & 4.7 & 2.3 & 9.3 & 32.6 & 41.9 & 9.3 & +84 \\
\hline 2 & 7.8 & 35.3 & 31.4 & 19.6 & 3.9 & 2.0 & -75 & 9.3 & 25.6 & 30.2 & 30.2 & 4.7 & 0.0 & -65 \\
\hline 3 & 3.9 & 3.9 & 17.6 & 39.2 & 25.5 & 9.8 & +75 & 2.3 & 9.3 & 4.7 & 27.9 & 51.2 & 4.7 & +84 \\
\hline 4 & 5.9 & 19.6 & 39.2 & 29.4 & 5.9 & 0.0 & -65 & 11.6 & 18.6 & 25.6 & 30.2 & 11.6 & 2.3 & -56 \\
\hline 5 & 3.9 & 23.5 & 13.7 & 37.3 & 13.7 & 7.8 & +59 & 2.3 & 7.0 & 23.3 & 37.2 & 25.6 & 4.7 & +68 \\
\hline 6 & 7.8 & 27.5 & 33.3 & 21.6 & 7.8 & 2.0 & -69 & 7.0 & 39.5 & 34.9 & 9.3 & 7.0 & 2.3 & -81 \\
\hline 7 & 0.0 & 3.9 & 33.3 & 37.3 & 17.6 & 7.8 & +63 & 2.3 & 4.7 & 14.0 & 34.9 & 34.9 & 9.3 & +79 \\
\hline 8 & 0.0 & 2.0 & 15.7 & 58.8 & 21.6 & 2.0 & +82 & 4.7 & 4.7 & 7.0 & 37.2 & 37.2 & 9.3 & +84 \\
\hline 9 & 3.9 & 27.5 & 43.1 & 19.6 & 5.9 & 0.0 & -75 & 7.0 & 41.9 & 39.5 & 7.0 & 4.7 & 0.0 & -88 \\
\hline 10 & 0.0 & 2.0 & 17.6 & 52.9 & 23.5 & 3.9 & +80 & 2.3 & 0.0 & 9.3 & 37.2 & 44.2 & 7.0 & +88 \\
\hline II & 0.0 & 3.9 & 23.5 & 49.0 & 17.6 & 5.9 & +73 & 4.7 & 0.0 & 2.3 & 46.5 & 39.5 & 7.0 & +93 \\
\hline 12 & 5.9 & 13.7 & 17.6 & 51.0 & 11.8 & 0.0 & +63 & 4.7 & 4.7 & 23.3 & 34.9 & 32.6 & 0.0 & +68 \\
\hline 13 & 2.0 & 11.8 & 27.5 & 47.1 & 11.8 & 0.0 & +59 & 4.7 & 7.0 & 16.3 & 44.2 & 25.6 & 2.3 & +72 \\
\hline 14 & 3.9 & 5.9 & 45.1 & 31.4 & 9.8 & 3.9 & -55 & 4.7 & 2.3 & 16.3 & 48.8 & 23.3 & 4.7 & +77 \\
\hline 15 & 5.9 & 29.4 & 45.1 & 17.6 & 2.0 & 0.0 & -80 & 14.0 & 23.3 & 46.5 & 16.3 & 0.0 & 0.0 & -84 \\
\hline 16 & 2.0 & 17.6 & 23.5 & 35.3 & 17.6 & 3.9 & +57 & 4.7 & 7.0 & 14.0 & 60.5 & 11.6 & 2.3 & +74 \\
\hline 17 & 0.0 & 5.9 & 17.6 & 37.3 & 25.5 & 13.7 & +77 & 4.7 & 2.3 & 9.3 & 48.8 & 27.9 & 7.0 & +84 \\
\hline 18 & 11.8 & 37.3 & 31.4 & 13.7 & 5.9 & 0.0 & $-8 I$ & 20.9 & 32.6 & 34.9 & 2.3 & 9.3 & 0.0 & -88 \\
\hline 19 & 2.0 & 9.8 & 17.6 & 52.9 & 15.7 & 2.0 & +71 & 2.3 & 7.0 & 11.6 & 48.8 & 30.2 & 0.0 & +79 \\
\hline 20 & 0.0 & 3.9 & 17.6 & 49.0 & 25.5 & 3.9 & +78 & 2.3 & 7.0 & 7.0 & 32.6 & 44.2 & 7.0 & +84 \\
\hline 21 & 7.8 & 31.4 & 45.1 & 13.7 & 2.0 & 0.0 & -84 & 18.6 & 37.2 & 32.6 & 11.6 & 0.0 & $0.0-$ & 88 \\
\hline 22 & 23.5 & 19.6 & 33.3 & 11.8 & 9.8 & $2.0-$ & -76 & 9.3 & 11.6 & 27.9 & 30.2 & 16.3 & 4.7 & +51 \\
\hline 23 & 0.0 & 3.9 & 19.6 & 27.5 & 35.3 & 13.7 & +77 & 2.3 & 9.3 & 11.6 & 39.5 & 30.2 & 7.0 & +77 \\
\hline 24 & 3.9 & 13.7 & 29.4 & 27.5 & 15.7 & 9.8 & +53 & 4.7 & 18.6 & 30.2 & 34.9 & 11.6 & 0.0 & +54 \\
\hline 25 & 7.8 & 9.8 & 35.3 & 25.5 & 13.7 & 7.8 & -53 & 0.0 & 11.6 & 53.5 & 30.2 & 2.3 & 2.3 & -65 \\
\hline 26 & 2.0 & 11.8 & 23.5 & 25.5 & 23.5 & 13.7 & +63 & 4.7 & 4.7 & 37.2 & 37.2 & 14.0 & 2.3 & +54 \\
\hline 27 & 5.9 & 13.7 & 37.3 & 33.3 & 7.8 & 2.0 & -57 & 2.3 & 25.6 & 37.2 & 32.6 & 2.3 & 0.0 & -65 \\
\hline 28 & 5.9 & 23.5 & 31.4 & 31.4 & 7.8 & 0.0 & -61 & 20.9 & 16.3 & 27.9 & 30.2 & 2.3 & 2.3 & -56 \\
\hline 29 & 0.0 & 21.6 & 45.1 & 25.5 & 3.9 & 3.9 & -67 & 18.6 & 20.9 & 34.9 & 18.6 & 4.7 & 2.3 & -74 \\
\hline 30 & 3.9 & 3.9 & 21.6 & 58.8 & 9.8 & 2.0 & +70 & 2.3 & 2.3 & 16.3 & 53.5 & 18.6 & 7.0 & +79 \\
\hline
\end{tabular}

dents are able to teach and learn with their peers and so this approach appears sustainable.

The outcomes of learning preference and peer-teacher and peer-peer interactions are more diverse. While students enjoyed and valued the small group learning experiences there was a strong dependence on receiving the required information from a content expert. This is seen in their preferences relating to being given correct information rather than working from first principles, a preference for questioning and learning from teachers rather than from colleagues and an overall preference for learning from teacher-centred lectures than small group activities. While these outcomes seem to conflict with the educational intent of the course, students and perhaps particularly dental students, want to know the how, when and why a procedure or decision is made from the content expert. However, such passive learning does not necessarily instill deep learning and understanding in the student. Even though students appear to express a preference for this learning style it is not appropriate to change the course for this reason alone as deep learning and understanding is a process that does not occur with passive information transfer. ${ }^{18}$

This student-centred problem-orientated course is different to student's previous learning experiences which would have been tutor-centred and seminar/lecture driven. Such a radical change in comparison to students' previous learning experiences may have lead to a possible personal conflict with this learning approach that was different and required significant student participation. This may also be reflected in some of the students' responses showing a preference to being given the 'correct information' and 'learning from teachers rather than from...colleagues'.

It was interesting to note that there was support for the hypothesis that peer-peer explanations are understood as well or better than staff-students explanations because learners use a language that novices can understand in comparison to an expert. In a learning environment, particularly where the medium of instruction is not the 


\section{EDUCATION learning}

first language, content experts can use technical and elaborate terminologies that neophytes may have difficulty understanding.

Generally the 5th-year students were more positive to the programme than the 4th-year students. This may be because they completed the questionnaire one year after taking the course. This would have given them more time to reflect and apply the knowledge gained from the course clinically which the 4th-year students did not have when completing the questionnaire soon after finishing the course. This may also account for the discrepancy of opinion regarding the small group tutorials and conventional lectures or may reflect genuine differences between the two years of students or that the fifth year of students cannot recall exactly how they behaved and responded to the course.

Further investigations are needed into understanding the rationale of student dependence on teacher-centred activities to allow appropriate improvements to student-centred courses thereby alleviating student perceptions of the need for continuous teacher-centred guidance. This may involve a more thorough briefing of the educational aims of the course and that tutors will answer any questions or problems students may have after the worksheet debriefing.

This questionnaire evaluates a dental course and gains insight into students learning preferences with the different aspects of the course. The evaluation questionnaire is one dimensional in understanding students' thoughts, it does not allow a deeper understanding that a structured interview may allow with appropriate follow up questions. From this shortcoming we see the responses to the questionnaire raise many interesting issues for further possible research. Student interviewing could help understand why students enjoy small-group activities and which type of student interactions are most beneficial to learning. In particular an understanding of the apparent conflict of students enjoying and preferring peer-peer interactions but wanting knowledge from content experts.

\section{Conclusion}

The small-group problem-orientated learning activities associated with this FPD course appear to have allowed the opportunity for an interactive, elaborative and enjoyable learning environment allowing beneficial peer-peer interactions such as discussion, clarification of facts, questions, concepts and peer teaching which are known to facilitate learning. However this type of learning approach may not suit all learners particularly if embedded in a traditional tutor-centred curriculum.

1. Reynolds M. Groupwork in education and training - ideas in practice. 1st ed. London: Kogan Page Limted, 1994.

2. Joyce B, Weil M. Models of teaching. Hemel Hempstead: Allyn and Bacon, 1972.

3. Slavin R E. Cooperative learning: theory, research and practice. 2nd ed. Massachusetts: Allyn and Bacon, 1995.

4. Johnson D W, Johnson R T. Learning together and alone. Englewood Cliffs, NJ, USA: Allyn and Bacon, 1991.

5. Damin W. Peer education: the untapped potential. J Appl Devel Psychol 1984; 5: 331-343.

6. Devin-Sheehan L, Feldman R, Allen V. Research in children tutoring children: a critical review. Rev Educ Res 1976; 46 : 355-385.

7. Anderson J R, Reder L M. An elaboratorive processing explanation of depth of processing. In Craik F M (ed). Levels of Processing in Human Memory. Hillsdale, NY: Erlbaum, 1979.

8. Iwasiw C L, Goldenberg D. Peer teaching among nursing students in the clinical area: effects on student learning. J Adv Nurs 1993; 18: 659-668.

9. Ames G J, Murray F B. When two wrongs make a right: Promoting cognitive change by social conflict. Devel Psychol 1982; 18: 894-897.

10. Anderson R C. The notion of schemata and the educational enterprise: general discussion of the conference. In Anderson R C, Spiro R J, Montague W E (eds). Schooling and the acquisition of knowledge. Hillsdale, NY. Erlbaum, 1977.

11. Rumelhart D E, Ortony E. The representation of knowledge in memory. In Anderson R C, Spiro R J, Montague W E (eds). Schooling and the acquisition of knowledge. Hillsdale, NY. Erlbaum, 1977.

12. Tulving E, Thompson D M. Encoding specificity and retrieval processes in episodic memory. Psych Rev 1973; 80: 352-373.

13. Bargh J A, Schul Y. On the cognitive benefits of teaching. J Educ Psych 1980; 72: 593-604.

14. Likert R. A technique for the measurement of attitudes. Arch Psychol 1932; 40: 1-55.

15. Moser C A, Kalton G. Survey methods in social investigations. 2nd ed. London: Heinmann, 1980.

16. Cronbach L J. Coefficient alpha and the internal structure of tests. Psychometrica 1951; 16: 297-334.

17. Cattel R B. The scree test for the number of factors. Behav Res 1966; 1: 245-276.

18. Biggs J B. What and how do Hong Kong students learn? Using the learning and study process questionnaires. Education paper. Hong Kong: Hong Kong University, 1992. Report No. 14. 